\title{
Measuring patient trust: comparing measures from a survey and an economic experiment
}

\begin{abstract}
Despite its importance in healthcare, empirical evidence on patient trust is limited. This is likely because, as with many complex concepts, trust is difficult to measure. This study measured patient trust in healthcare providers in a sample of 667 patients in Senegal. Two instruments were used to measure patient trust in providers: a survey questionnaire and an incentivised behavioural economic experiment - a 'trust game'. The results show that the two measures are significantly, but weakly, associated. Using information from patients and providers, we find that continuity of care, provider communication ability and clinical competence were positively associated with patient trust. Based on the results obtained from both methods, the trust game seems to have higher construct validity than the survey instrument in this context. This paper contributes to the methodological literature on patient trust and the evidence on the determinants of patient trust. It suggests that researchers interested in studying patient trust in providers should rely more on economic experiments and explore their validity in different contexts.
\end{abstract}

Keywords: trust, patient-provider relationship, trust game, Trust in Physician Scale, Senegal 


\section{INTRODUCTION}

A growing body of research indicates that trust is crucial for economic and social development. Trust can reduce the cost of economic transactions and make it easier for people to cooperate and share information (Arrow, 1972; Dearmon \& Grier, 2009; Durlauf, 2002; Putnam, 1993). Trust is also important in healthcare, especially in the relationship between patients and providers. According to the principal-agent framework (Arrow, 1985; Grossman \& Hart, 1983; Holmstrom, 1979), when patients (principals) seek medical care, they choose a provider (agent) to make decisions on their behalf. However, due to uncertainty in health care and asymmetry of information between patient and providers, patients cannot rely on a formal contract to ensure that the outcome of the interaction will be optimal for them (Holmstrom \& Milgrom, 1991; Mooney \& Ryan, 1993). This makes seeking healthcare a risky decision, as patients may visit providers who do not give the best medical advice or recommend unnecessary and costly treatments and procedures. Patients choosing to consult a provider, therefore have to expect that providers will not take advantage of their vulnerable situation, but instead act in their interest, as perfect agents would do. This expectation, often defined in the literature as patient trust (Hall, Dugan, Zheng, \& Mishra, 2001; Hillen, de Haes, \& Smets, 2011), can therefore be seen as a necessary ex-ante condition for patients to demand health care and enter an informal contract with providers. Because it relates to patients' perception that providers have their best interest at heart, trust is also key ex-post because it may influence whether patients will adhere to the recommendations made or medicines prescribed, therefore influencing health outcomes.

Despite its importance in healthcare, empirical evidence on patient trust is limited. A study in the USA found that low levels of patient trust in providers are linked to under-utilisation of healthcare (LaVeist, Isaac, \& Williams, 2009). Some studies have shown an association between higher patient trust in providers and higher patient satisfaction (Boothroyd, Della Rocca, \& Chen, 2008), or better adherence to medication (Altice, Mostashari, \& Friedland, 2001; Saha, Jacobs, Moore, \& Beach, 2010). An important challenge for empirical research on patient trust is the difficulty of measuring patient trust and the absence of a consensus on measurement tools. In the health literature, studies exploring patient trust in providers have used survey instruments (Brennan et al., 2013). Meanwhile, the economics literature on trust (looking at general levels of trust in societies) has favoured the use of a behavioural economic experiment (the 'trust game'), where individuals' responses have real monetary consequences (Berg et al., 1995; Johnson \& Mislin, 2011). Although surveys arguably provide a more intuitive and direct measure of trust, economists have argued that economic experiments generate better measures of trust, partly 
because incentivised decisions are less likely to suffer from a response bias (Glaeser, Laibson, Scheinkman, \& Soutter, 2000). However, in the absence of a gold standard measure of trust, this debate is difficult to settle. In this paper, we use both methodological approaches in the healthcare context and explore their construct validity, i.e. the degree to which a measure captures what it claims to be measuring (Cronbach \& Meehl, 1955).

This study makes two contributions. Firstly, it contributes to the limited methodological literature on the measurement of trust in general, and patient trust in providers in particular. To the best of our knowledge, this is the first study to use and contrast results from the two approaches used to measure trust in providers in the health and economics literature. Secondly, the results add to the empirical literature on patient trust in providers, by generating evidence from a low-income setting (Senegal), where trust and informal contracts are likely to play an important role in patients' care seeking decisions.

We find that patients in Senegal generally trust their healthcare providers. Measures of trust obtained from a survey instrument are weakly, but significantly, associated with measures obtained from a trust game. Higher levels of trust are found for providers with better clinical competence and communication skills. Finally, results suggest that the trust game seems to have somewhat higher construct validity than the survey instrument.

\section{LITERATURE REVIEW}

This section discusses the two methodological approaches used to measure trust - survey instruments and economic experiments - and reviews the empirical evidence on correlates of patient trust. Throughout, we make a distinction between generic trust (people's general sense of trust, without reference to particular individuals or groups) and specific trust (trust between two clearly defined entities such as specifically named individuals or groups).

\subsection{Measuring trust with surveys}

Survey instruments have been used to measure generic as well as specific trust. Most surveys measure generic trust with a single question: "Generally speaking, would you say that most people can be trusted or that you can't be too careful in dealing with people?". This question appears, for example, in the World Values Survey, the General Social Survey as well as the European Social Survey (Alesina \& La Ferrara, 2002; Knack \& Keefer, 1997).

To conceptualise trust in specific domains, survey instruments have been developed to measure specific trust, for example, between business partners (Zaheer, McEvily, \& Perrone, 1998) or in 
close inter-personal relationships (Larzelere \& Huston, 1980). Several instruments have been developed to measure patient trust in providers. The most commonly used in the health literature is the Trust in Physician Scale (TiPS) (Anderson \& Dedrick, 1990). This tool has been found to have high internal consistency and reliability (Freburger, Callahan, Currey, \& Anderson, 2003; Thom, Ribisl, Stewart, \& Luke, 1999). The TiPS consists of a list of eleven statements such as "My provider is usually considerate of my needs and puts them first" or "I trust my provider's judgement about my medical care", which patients score using five-point Likert scale (for a full list, see online Appendix 1).

\subsection{Measuring trust with economic experiments}

Economists often use behavioural economic experiments to measure trust (Berg et al., 1995; Johnson \& Mislin, 2011). They usually use an experiment called the trust game, or investment game. It is a simple decision task played for real money by two individuals: a truster and a trustee. One individual (truster) receives a monetary endowment and chooses how much of this endowment they want to send to a second individual (trustee). Any amount sent by the truster is multiplied by the experimenter, and the trustee who receives it has to decide which proportion to return to the truster. The amount of money sent by the truster is interpreted as a measure of their trust in the trustee. This relates to the definition of trust usually used in economics. According to James (2002), saying that A trusts B means that A expects that B will not exploit A when A is vulnerable (p.291). The trust game arguably measures this type of trust as the truster will only send money in the trust game if they expect that the trustee will reciprocate part of their generosity and not exploit it to their own benefit (i.e. if they expect a return transfer).

Since Berg (1995) developed the trust game, almost 200 have been conducted in low as well as high-income settings (Johnson \& Mislin, 2011). Trust games are primarily used to measure generic trust, as most are conducted with subjects (frequently students) that have little or no information about one another (Johnson \& Mislin, 2011). However, some studies have used trust games to measure specific trust, for example, between spouses (Castilla, 2015) or friends (Binzel $\&$ Fehr, 2013). To our knowledge, the trust game has not been used to measure trust between patients and providers.

\subsection{Comparing the two methods}

Whether economic games or survey instruments provide better measures of trust is much debated. The main concern with surveys is that respondents' answers are likely to be influenced by what they perceive as socially acceptable (Krumpal, 2013; Paulhus, 1991). As a result, survey 
measures can over- or under-estimate true levels of trust. Economists have argued that this is not a concern for trust games for two reasons (Glaeser et al., 2000). First, in a trust game, subjects' make decisions anonymously. Second, because decisions in trust games have real monetary consequences, individuals are more likely to reveal their true levels of trust. However, trust games have other limitations, as several studies have pointed out, players' decisions are not simply determined by their level of trust. In some instances, choices in the trust game are also likely to capture cultural or social norms. For example, in a study in Bangladesh, when asked why they sent money in the trust game, half of respondents mentioned "fear of punishment after death" as the main reason (Johansson-Stenman, Mahmud, \& Martinsson, 2013). Furthermore, several studies find that decisions are also influenced by individuals' risk aversion (Karlan, 2005; Schechter, 2007) or altruism (Ashraf, Bohnet, \& Piankov, 2006; Cox, 2004).

Some studies have examined whether survey and experimental measures of trust are correlated. Most of the results pertain to measures of generic trust and show mixed evidence. Some studies indicate that the two measures are uncorrelated (for example, Ashraf, Bohnet, \& Piankov, 2006; Glaeser, Laibson, Scheinkman, \& Soutter, 2000; Holm \& Nystedt, 2008), whilst others find a positive relationship (for example, Bellemare \& Kröger, 2003; Sapienza, Toldra-Simats, \& Zingales, 2013). To the best of our knowledge, only one study, undertaken in villages in Cameroon, compares measures of specific trust (Etang et al., 2012). The measures of trust between fellow villagers elicited with a survey and a trust game were found to be positively associated (Etang et al., 2012).

In this study, we seek to go beyond the simple correlation of measures and explore the validity of a trust game and a trust survey by using other information from respondents to capture the construct validity of both measures.

\subsection{Determinants of patient trust}

Most of the evidence on the determinants of patient trust comes from high-income settings, primarily North America (for a review, see Murray \& McCrone, 2015). Only a handful of studies have been conducted in low and middle-income countries (LMICs) such as China (Zhao, Rao, \& Zhang, 2016), Taiwan (Lee \& Lin, 2011) or Cambodia (Ozawa \& Walker, 2011). Yet, it is particularly relevant to study patient trust in such settings, as levels of care seeking are often low (for example, Herbert, Lee, Chandran, Rudan, \& Baqui, 2012) and a lack of trust could be a contributing factor. 
The empirical literature on the determinants of patient trust in providers has explored a limited range of factors. Most studies examine the association between trust and basic sociodemographic patient characteristics (gender, age, ethnic group), but very few have explored the role of provider characteristics (for a review, see Murray \& McCrone, 2015). This is despite the fact that several provider attributes are a priori likely to influence patients' expectation of receiving correct treatments. For example, clinical competence has been highlighted as one of the key determinants of patient trust by qualitative studies (for example, Mechanic \& Meyer, 2000). Other aspects, such as providers' communication skills are also likely to influence the patient's belief about the extent to which the provider cares about their case, and their well-being in general (Fiscella et al., 2004).

\section{DATA}

\subsection{Study setting and design}

This study took place in Senegal, a low-income country with a GDP per capita of 1,044 USD (WB, 2016). Data were collected in a random sample of 184 primary care facilities located in four rural regions (Ziguinchor, Sédhiou, Tambacounda, Kédougou). These areas are particularly disadvantaged compared to the rest of the country. About two thirds $(68.6 \%)$ of households fall in the two poorest quintiles (DHS, 2015), and nearly half of the adult population is illiterate (ANSD, 2015). Utilisation of health services is low, as $65 \%$ of households did not seek care when their child was last ill (DHS, 2015). Patients who seek care primarily access government facilities, generally health posts and health centres - which is where this study took place. Bribing is uncommon in public healthcare facilities in Senegal. Data from the Afrobarometer survey suggest that only $11 \%$ of respondents felt like they had to do a favour or give a bribe or gift to a public provider in the past (Kankeu \& Ventelou, 2016). Unfortunately, no disaggregated data are available to indicate the frequency of informal payments in study areas. The analysis uses four sources of data, collected between April and July 2016. Data from 667 patient exit interviews are used to obtain socio-demographic information about patients, their perception of providers' communication abilities as well as a survey measure of their trust in providers. A behavioural measure of trust was obtained from a trust game implemented between those 667 patients and the 258 providers who consulted them. Furthermore, we use data from a provider survey to capture socio-demographic characteristics and a measure of clinical knowledge. Finally, data from a facility survey provides basic information about each healthcare facility. 
Ethical approval for the study was obtained from the Research Ethics Committees of the London School of Hygiene and Tropical Medicine, and the Ministry of Health in Senegal.

\subsection{Patient survey data}

In each facility visited, four patients were invited to take part in the study immediately after completing their consultations. All patients who were approached agreed to participate.

The patient questionnaire included a short module to collect socio-demographic information, including the type of consultation the patient attended. Patients were asked to rate four aspects of providers' communication skills during the consultation (greeting them, looking at them whilst speaking, providing information and telling them when to return). To measure patient trust in the provider, the questionnaire included the TiPS presented earlier. Patients were asked to give answers in reference to the provider they had just consulted.

\subsection{Trust game}

The second measure of trust used in this study was obtained through a trust game conducted with patients and their primary healthcare providers. In order to avoid a potential selection bias, participants were not told beforehand that they would be able to gain monetarily by taking part.

The trust game was played at the end of the patient survey. Patients were given 1,000 FCFA $(€ 1.50)$ and three options: keep everything, send 500 FCFA or send 1,000 FCFA to the healthcare provider they had just seen. Any amount sent by the patient was tripled before it was given to providers. Patients were informed that providers had previously decided what to do with any money received from patients, and that they could: return nothing, half or all of the money.

To minimise the time that patients spent waiting for a potential return transfer from providers, providers' choices were elicited the day before using the strategy method. Specifically, all providers in the facility were asked to indicate privately how much they would return to a patient in the two possible scenarios (patient sending half or all of the 1,000 FCFA). As the identity of patients was not known at the time, providers were told that they would be paired with "patients who come to this facility". However, when taking part in the game, patients knew that they were paired with the provider they had just seen in the consultation - whom they were asked to identify. These experimental procedures ensured that patients would not fear any retribution from providers, making it more likely that patients would reveal their true level of trust.

As the endowment was given in cash, patients understood that the trust game was played for real money. The game was played in a quiet space and patients made their decision privately - with 
the experimenter turning their back when patients decide how much money to transfer. Patients were paid shortly after making their decision, and providers were paid at the end of the following day, for one randomly selected patient.

To ensure that all participants understood the game, simple visual aids were developed to describe the different options. The game was piloted several times. Each time, participants were debriefed to ascertain their understanding and refine the visual aids and instructions. Enumerators were extensively trained to follow a script, in order to ensure that instructions were identical for all participants. Further information on logistics, as well as the specific instructions given to patients and providers can be found in the online Appendix 2.

\subsection{Provider and facility surveys}

To obtain a measure of clinical competence, healthcare providers were invited to complete up to seven clinical vignettes - reflecting the types of consultations they usually conduct (see Appendix 3 for full case descriptions). Clinical vignettes have been used in several studies to measure providers' clinical knowledge (Das et al., 2015; Mohanan et al., 2015). In the clinical vignettes used here, the main complaint of a fictitious patient was explained, and the provider was then asked how they would proceed. One enumerator played the role of the patient and responded to providers' questioning according to a script, whilst another recorded the questions asked, the examinations done, and the treatment and advice recommended by the provider.

Finally, a short survey was administered to the facility manager to collect basic information about the quality of infrastructure (availability of drugs and equipment) and facility type.

\subsection{Statistical analysis}

Two measures of patient trust are used as dependent variables in the analysis.

A 'survey measure' of trust is generated by aggregating responses from the eleven TiPS statements using principal factor analysis. This is done to determine whether the eleven statements in the TiPS capture one underlying construct. Only one factor had an eigenvalue greater than one and explained $73 \%$ of the total variance. To obtain a single measure of trust, we generate an aggregate score running from 0 to 100, which weighs each item by its factor loading in an iterated principal factor analysis with varimax rotation (see Appendix 1).

The 'behavioural measure' of trust uses patients' responses from the trust game. Following previous studies, the amount of money sent by patients $(0 \%, 50 \%, 100 \%)$ is used to measure patients' trust in the provider. 
Given the absence of a gold standard for measuring trust, we explore the "performance" of both measures of patient trust by examining their construct validity. In their comprehensive review of the literature, Murray and McCrone (2015) summarise a series of patient and provider characteristics expected to be associated with patient trust. Table 1 summarises the characteristics captured in this study and indicates the expected direction of their association with patient trust. These characteristics are used to assess the construct validity of the two measures of trust.

Table 1: Overview of determinants of patient trust

\begin{tabular}{|l|l|l|}
\hline Variable & Rationale & Expected Direction \\
\hline Patient education & $\begin{array}{l}\text { More educated patients have different criteria for } \\
\text { assessing whom they trust }\end{array}$ & Unclear \\
\hline Continuity of care & Trust develops over time & Positive \\
\hline Patient ethnic group & Patients from minority groups have lower levels of trust & Lower for minorities \\
\hline Provider gender & Used by patients to assess competence & $\begin{array}{l}\text { Higher for male } \\
\text { providers }\end{array}$ \\
\hline Type of consultation & $\begin{array}{l}\text { Patients coming for curative consultations have different } \\
\text { criteria for assessing whom they trust }\end{array}$ & Unclear \\
\hline Provider ethnic group & Used by patients to assess competence & Lower for minorities \\
\hline Provider skill position & Used by patients to assess competence & Positive \\
\hline $\begin{array}{l}\text { Provider } \\
\text { communication ability }\end{array}$ & Signals caring & Positive \\
\hline $\begin{array}{l}\text { Provider clinical } \\
\text { competence }\end{array}$ & $\begin{array}{l}\text { Determines providers' ability to achieve positive patient } \\
\text { outcomes }\end{array}$ & Positive \\
\hline $\begin{array}{l}\text { Provider from same } \\
\text { ethnic group as patient }\end{array}$ & $\begin{array}{l}\text { Patients place more trust in people who are similar to } \\
\text { them }\end{array}$ & Positive \\
\hline
\end{tabular}

We first present descriptive evidence on patient trust. We then explore whether there is an association between survey and behavioural trust using linear multi-level regressions. To explore construct validity, both measures of trust are regressed on patient, provider and facility characteristics in the following specification:

$$
Y_{i j}=\beta_{0}+\beta_{1} X_{i j}+\beta_{2} Z_{j}+\beta_{3} F_{j}+\varepsilon_{i j}+u_{j}
$$

where $Y_{i j}$ is the measure of trust (survey or behavioural), $X_{i j}$ is a vector of patient characteristics, $Z_{j}$ is a vector of provider characteristics and $F_{j}$ is a vector of facility characteristics. We use linear and ordered multi-level regressions to take into account that data are hierarchical (in the sense that multiple patients $i$ indicate how much they trust the same provider $j$ ). Hence, the residual is split into two components, reflecting the two levels in the data: $u_{j}$ captures the grouplevel residual and $\varepsilon_{i j}$ the individual residual. 


\section{RESULTS}

\subsection{Patient trust in providers}

Descriptive statistics of patient and healthcare provider characteristics are presented and briefly discussed in online Appendix 5. This section provides a descriptive overview of the behavioural and survey measures of trust.

In the trust game, as shown in Figure 1, the majority of patients $(57.1 \%)$ sent half of their endowment, while $6.5 \%$ chose to send nothing. Overall, the average amount sent is $65 \%$ of the initial endowment. Sending money was a good investment decision for most patients, as only $1.2 \%$ of patients received less than the amount sent.

The survey measure of trust is heavily skewed towards high levels of trust (see Figure 2). The average survey score is 88.1 out of 100 (with a standard deviation of 9.4). Only three patients scored below 50, and $11 \%$ of patients have the maximum score of 100 .

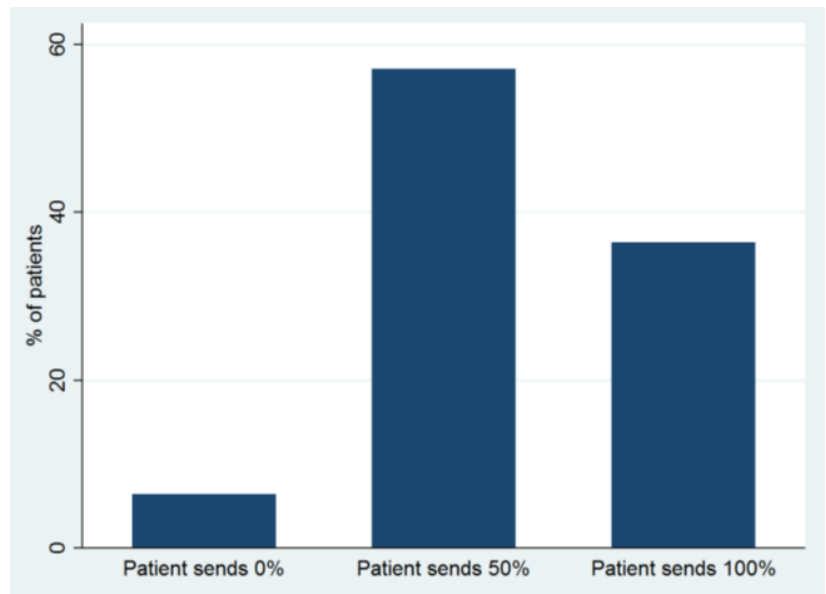

Figure 1: Behavioural trust, amount sent in the trust game by 667 patients in rural Senegal in 2016

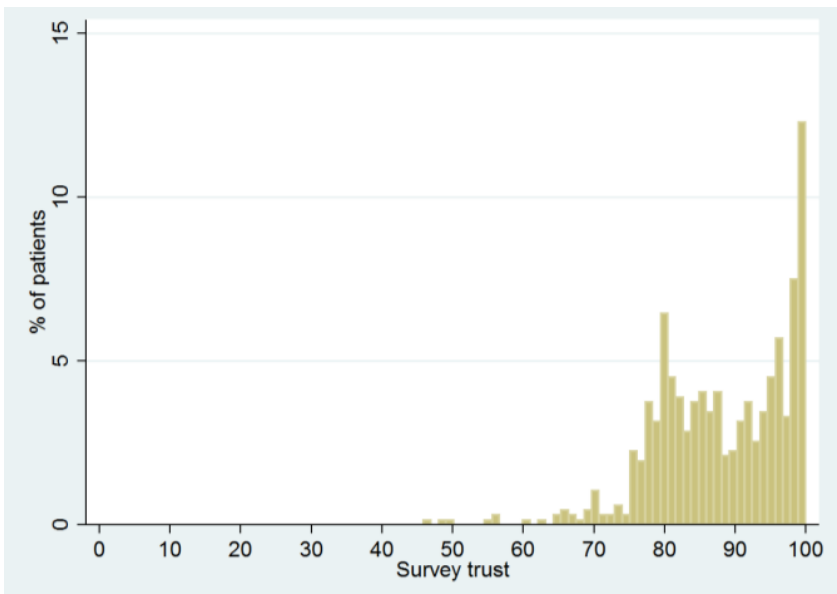

Figure 2: Survey trust, TiPS scores for 667 patients in rural Senegal in 2016

\subsection{Trust in games and surveys}

Turning to the association between the two measures of trust, we first plot the amount sent by each patient in the trust game against their trust survey score (Figure 3). From this representation, no relationship between the two scores is immediately apparent. Nonetheless, patients who sent everything in the trust game seem concentrated around high levels of survey trust. Similarly, all patients who score below 60 in the trust survey sent none or half of their endowment. 


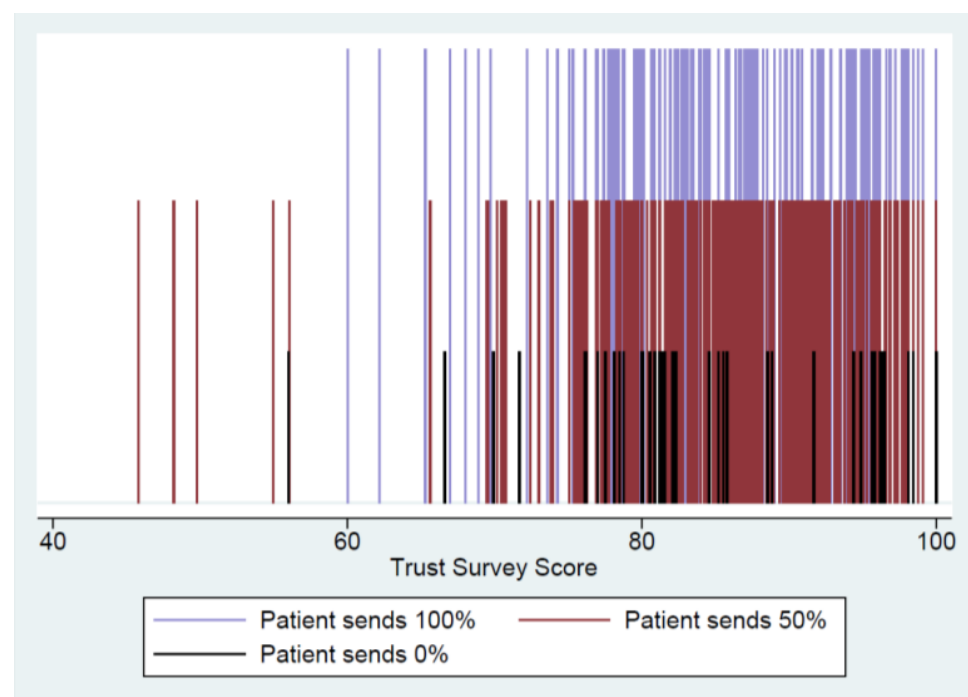

Figure 3: Survey and behavioural trust scores for 667 patients in rural Senegal

Table 2 reports regressions of survey trust on behavioural trust using linear multi-level regressions. Model 1 does not include any other variables and Model 2 controls for patient and provider characteristics. The association between the two measures of patient trust is statistically significant in both models, but of a relatively small magnitude. For patients who sent none of their endowment, rather than all of their endowment, the average trust survey score decreases by $3.6 \%$ or 0.34 standard deviations, all else equal. Patients who sent half of their endowment (rather than all) have an average trust survey score that is $1.3 \%$ lower ( 0.15 standard deviations), all else equal.

Table 2: Survey trust and behavioural trust (linear multi-level regressions)

\begin{tabular}{ccc}
\hline & \multicolumn{2}{c}{ Survey } \\
\hline Patient sends 100\% & $(1)$ & $(2)$ \\
Patient sends 0\% & $-0.343^{* *}$ & $-0.337^{* *}$ \\
$\quad$ Patient sends 50\% & $(0.148)$ & $(0.147)$ \\
& $-0.152^{* *}$ & $-0.126^{*}$ \\
Patient and provider characteristics: & $(0.0745)$ & $(0.0745)$ \\
Number of groups (providers) & & $Y E S$ \\
Observations (patients) & 258 & 258 \\
\hline
\end{tabular}

Note: Association between survey and behavioural trust for 667 patients in rural Senegal. Data were collected in 2016. A standardized trust survey score is used in both models. Model 2 controls for patient literacy, the type of consultation, patient ethnic group, provider sex, provider ethnic group and facility type. Standard errors in parentheses: $* * * \mathrm{p}<0.01, * * \mathrm{p}<0.05, * \mathrm{p}<0.1$ 


\subsection{Determinants of patient trust}

This section investigates the correlates of patient trust. All results presented here are robust to alternative specifications (see Appendix 6). The proportional odds assumption is not violated for any of the ordered models presented below.

Models 1 to 3 in Table 3 show that three relevant variables are associated with survey trust. Patients who are literate in French score slightly lower on the trust survey. Patients who visited their provider before score 0.6 standard deviations higher on the trust survey, and those who saw a communicative provider score 0.5 standard deviations higher.

Table 3: Determinants of patient trust (linear and ordered multilevel regressions)

\begin{tabular}{|c|c|c|c|c|c|c|}
\hline & \multicolumn{3}{|c|}{ Trust survey } & \multicolumn{3}{|c|}{ Trust game } \\
\hline & (1) & (2) & $(3)$ & (4) & $(5)$ & $(6)$ \\
\hline \multirow[t]{2}{*}{ Patient reads French } & $-0.156^{* *}$ & $-0.185^{* *}$ & $-0.182 * *$ & 0.899 & 0.933 & 0.863 \\
\hline & $(0.0716)$ & $(0.0741)$ & $(0.0732)$ & $(0.178)$ & $(0.186)$ & $(0.170)$ \\
\hline \multirow[t]{2}{*}{ Patient visited provider before } & $0.617 * * *$ & $0.646 * * *$ & $0.646 * * *$ & $1.448^{*}$ & $1.494 * *$ & $1.532 * *$ \\
\hline & $(0.0720)$ & $(0.0743)$ & $(0.0743)$ & $(0.286)$ & $(0.293)$ & $(0.303)$ \\
\hline \multirow[t]{2}{*}{ Type of consultation (curative) } & 0.0277 & -0.0942 & -0.0870 & 0.782 & 0.795 & $0.711^{*}$ \\
\hline & $(0.0780)$ & $(0.0799)$ & $(0.0787)$ & $(0.163)$ & $(0.165)$ & $(0.146)$ \\
\hline \multirow[t]{2}{*}{ Male provider } & $0.172 *$ & 0.163 & 0.144 & 1.355 & $1.479 *$ & 1.330 \\
\hline & $(0.0990)$ & $(0.106)$ & $(0.104)$ & $(0.297)$ & $(0.327)$ & $(0.295)$ \\
\hline \multirow[t]{2}{*}{ Unskilled Provider } & -0.108 & -0.128 & -0.103 & $0.434 * *$ & 0.563 & $0.441 * *$ \\
\hline & $(0.150)$ & $(0.164)$ & $(0.158)$ & $(0.148)$ & $(0.197)$ & $(0.153)$ \\
\hline \multirow[t]{2}{*}{ Communicative provider } & $0.504 * * *$ & & & $1.570^{* *}$ & & \\
\hline & $(0.0724)$ & & & $(0.316)$ & & \\
\hline \multirow[t]{2}{*}{ Provider clinical competence } & & 0.00108 & & & $1.023 * * *$ & \\
\hline & & $(0.00321)$ & & & $(0.00700)$ & \\
\hline \multirow[t]{2}{*}{ Patient from minority group } & 0.137 & 0.146 & & 0.862 & 0.777 & \\
\hline & $(0.167)$ & $(0.173)$ & & $(0.391)$ & $(0.353)$ & \\
\hline \multirow[t]{2}{*}{ Provider from minority group } & -0.127 & -0.0873 & & 1.022 & 0.962 & \\
\hline & $(0.122)$ & $(0.130)$ & & $(0.270)$ & $(0.256)$ & \\
\hline From same ethnic group & & & $\begin{array}{c}-0.0279 \\
(0.0920)\end{array}$ & & & $\begin{array}{c}0.878 \\
(0.197)\end{array}$ \\
\hline Number of groups (providers) & 258 & 258 & 258 & 258 & 258 & 258 \\
\hline Observations (patients) & 667 & 667 & 667 & 667 & 667 & 667 \\
\hline
\end{tabular}

Note: Determinants of patient trust for 667 patients in rural Senegal. Data were collected in 2016. A standardized trust survey score is used in Model 1 - Model 3 (linear multi-level regressions). An ordinal measure of the amount sent in the trust game is used in Model 4 - Model 6 (ordered multi-level regressions.). Consultation type is coded as curative or not curative (ante-natal or family planning visit). All models control for the following variables that were not significantly associated with either measure of trust: facility type (health post or health centre), quality of infrastructure in facilities, low consultation volumes (less than 4 patients on the day data were collected), provider work experience in the facility. Standard errors in parentheses. ${ }^{* * *} \mathrm{p}<0.01,{ }^{* *} \mathrm{p}<0.05,{ }^{*} \mathrm{p}<0.1$

Models 4 to 6 show that four relevant variables are associated with behavioural trust. The probability of sending a larger endowment is $30 \%$ higher for patients who visited the provider before and for those who saw a communicative provider. We find evidence that provider clinical 
competence is associated with behavioural trust. Patients send less to unskilled providers, as well as those with lower clinical competence. The probability of sending a larger endowment is $40 \%$ lower when the provider is unskilled. The probability of sending all of the endowment is 0.24 for providers who completed $20 \%$ of items in the vignettes correctly, 0.36 for those who completed half of the items correctly and 0.60 for providers who completed all relevant items in the vignettes correctly.

\section{DISCUSSION AND CONCLUSION}

Our results show that in a context where few patients seek care, those who do have high levels of trust in providers. Levels of survey trust found here are high relative to comparable studies using the TiPS. For example, a study with Chinese patients reported a mean score of 64 (compared to our mean of 88) (Zhao et al., 2016). Whilst respondents' answers in the survey might be affected by social expectations (thereby exaggerating true levels of trust), our behavioural measure of trust - which is arguably not subject to such a bias - also indicated high levels of trust. In the trust game, $65 \%$ of the endowment was sent on average and only $6.5 \%$ of patients did not send anything. These results are similar to trust games conducted in comparable contexts, for example in Cameroon, where the average amount sent was $74 \%$ of the initial endowment (Etang et al., 2012).

This study provides evidence on the correlates of patient trust in providers in a low-income setting. Even though the role of competence in trust has been explored in other settings (Johnston, Mills, \& Landrum, 2015), this study is the first to examine whether patient trust is empirically associated with provider clinical competence, which is a priori plausible. Patients sent higher proportions of their endowment to skilled providers and to those with a higher level of clinical competence. In line with what has been found in some high-income settings, in this low-income setting, patient trust is negatively associated with patient education and positively associated with continuity of care and provider communication ability (for a review, see Murray \& McCrone, 2015).

Our measures of survey and behavioural trust are significantly associated, although the association is not very strong. This indicates that even though the two measures appear to capture similar concepts, there are also substantial differences. When examining the construct validity of both measures of trust we find that the behavioural measure is associated with a larger number of relevant factors than the survey measure of trust. This suggests that the trust game has somewhat higher construct validity. Hence, even though trust games are much more complex 
logistically and substantially more costly, they do appear to produce measures of trust with higher validity. This might be because patients over-state their true levels of trust in the survey to conform to social expectations (Krumpal, 2013; Paulhus, 1991). In this study, social expectations are likely to be highly relevant as patients are asked if they trust the provider they just consulted and might be unwilling to admit that they actually do not trust the person they have just relied on for a service. Another plausible explanation would be that it is monetarily costly for patients to deviate from their true preferences in the trust game, whilst this is not the case in the survey (Johansson-Stenman et al., 2013).

There are potential ethical concerns with conducting a trust game with patients and healthcare providers. To begin with, patients might fear future retribution from providers if they did do not transfer anything. To alleviate such concerns, the anonymity of patients was maintained - as providers were not aware who they were paired with. Providers were also paid for a randomly selected patient, which added to this anonymity. Another potential concern is that patients who did not receive a return transfer from providers would be less trusting in providers in the future. However, this was not an issue in this study as all but $1 \%$ of patients received less than what they had sent.

This study is limited in several respects. To begin with, patients only had a restricted number of choices in the trust game. Given more options, patients could have expressed their trust in providers in a more nuanced way. However, for logistical reasons as well as to avoid placing an added cognitive burden on participants (associated with a game of increased complexity), we decided to limit the number of options available to patients. Another potential shortcoming relates to the limited number of relevant variables used when assessing construct validity. For example, previous studies have highlighted that factors such as patient insurance status or income (Zhao et al., 2016) are associated with patient trust. Insurance status is not pertinent in the study setting and income is difficult elicit and was unlikely to vary substantially in the study population (DHS, 2015). Nonetheless, findings may have been affected by residual confounding due to known, as well as unknown confounders that were not included in the analysis.

In order to substantiate and expand the work presented here, further research should be conducted in other contexts, to determine the external validity of the findings. This study was conducted in a relatively poor segment of the population living in rural areas in Senegal. Even though Senegal is not dissimilar from other LMICs (particularly in West Africa) in terms of its main health system characteristics, it stands out in terms of religious and ethnic homogeneity and the stability 
of its political institutions. It is therefore unclear whether findings would hold in more urban areas or in other LMICs. Moreover, future studies in LMICs should attempt to relate different measures of patient trust to patient-level outcomes such as care seeking, health status or medication adherence - as has been done in high-income settings. If some measures of patient trust are related to these important outcomes, whilst other are not, this would provide further valuable evidence on construct validity. 


\section{REFERENCES}

Alesina, A., \& La Ferrara, E. (2002). Who trusts others? Journal of Public Economics, 85, $207-$ 234.

Altice, F. L., Mostashari, F., \& Friedland, G. H. (2001). Trust and the acceptance of and adherence to antiretroviral therapy. Journal of Acquired Immune Deficiency Syndromes (1999), 28(1), 47-58.

Anderson, L. A., \& Dedrick, R. F. (1990). Development of the Trust in Physician scale: a measure to assess interpersonal trust in patient-physician relationships. Psychological Reports, 67(3 Pt 2), 1091-100. http://doi.org/10.2466/pr0.1990.67.3f.1091

ANSD. (2015). SENEGAL - Enquête sur la Pauvreté et la Structure Familiale. Available at: http://www.ansd.sn/ressources/rapports/ANSD_EPSF2_rapportfinal2-def.pdf.

Arrow. (1985). The economics of agency. In Pratt, J., Zeckhauser, R. (Eds.), Principals and Agents: The Structure of Business (p. 37-51.). Boston: Harvard University Press.

Arrow, K. (1972). Gifts and Exchanges. Philosophy \& Public Affairs, 1(4), 343-362. http://doi.org/10.2307/2265097

Ashraf, N., Bohnet, I., \& Piankov, N. (2006). Decomposing trust and trustworthiness. Experimental Economics, 9(3), 193-208. http://doi.org/10.1007/s10683-006-9122-4

Bellemare, C., \& Kröger, S. (2003). On Representative Trust. SFB 373 Discussion Papers.

Berg, J., Dickhaut, J., McCabe, K., Guth, W., Palfrey, T., Sellen, R., ... McCabe, K. (1995). Trust, Reciprocity, and Social History. Games and Economic Behavior, 10(1), 122-142.

Binzel, C., \& Fehr, D. (2013). Social distance and trust: Experimental evidence from a slum in Cairo. Journal of Development Economics, 103(1), 99-106. http://doi.org/10.1016/j.jdeveco.2013.01.009

Boothroyd, R. A., Della Rocca, T., \& Chen, H. J. (2008). Predictors of enrollees' satisfaction with a county-sponsored indigent health care plan. Evaluation and the Health Professions, 31(1), 81-103. http://doi.org/10.1177/0163278707311882

Brennan, N., Barnes, R., Calnan, M., Corrigan, O., Dieppe, P., \& Entwistle, V. (2013). Trust in the health-care provider - patient relationship : a systematic mapping review of the evidence base. International Journal for Quality in Health Care, 25(6), 682-688. http://doi.org/10.1093/intqhe/mzt063

Castilla, C. (2015). Trust and Reciprocity between Spouses in India. American Economic Review, 105(5), 621-624. http://doi.org/10.1257/aer.p20151117

Cox, J. C. (2004). How to identify trust and reciprocity. Games and Economic Behavior, 46(2), 260-281. http://doi.org/10.1016/S0899-8256(03)00119-2

Cronbach, L., \& Meehl, P. (1955). Construct validity in psychological tests. Psychological Bulletin, 52(4), 281-302. http://doi.org/10.1037/h0040957

Das, J., Kwan, A., Daniels, B., Satyanarayana, S., Subbaraman, R., Bergkvist, S., ... Pai, M. (2015). Use of standardised patients to assess quality of tuberculosis care: A pilot, crosssectional study. The Lancet Infectious Diseases, 15(11), 1305-1313. http://doi.org/10.1016/S1473-3099(15)00077-8 
Dearmon, J., \& Grier, K. (2009). Trust and development. Journal of Economic Behavior and Organization, 71(2), 210-220. http://doi.org/10.1016/j.jebo.2009.02.011

DHS. (2015). Senegal 2015 DHS Final Report. http://dhsprogram.com/what-wedo/survey/survey-display-489.cfm.

Durlauf, S. N. (2002). On the empirics of social capital. Economic Journal, 112(483), F459F479. http://doi.org/10.1111/1468-0297.00079

Etang, A., Fielding, D., \& Knowles, S. (2012). Are Survey Measures of Trust Correlated with Experimental Trust? Evidence from Cameroon. Journal of Development Studies, (July 2015), 1-15. http://doi.org/10.1080/00220388.2011.649263

Fiscella, K., Meldrum, S., Franks, P., Shields, C. G., Duberstein, P., McDaniel, S. H., \& Epstein, R. M. (2004). Patient Trust: Is it related to patient-centered behaviour of primarcy care physicians? Medical Care, 42(11), 1049-1055. http://doi.org/10.1097/00005650200411000-00003

Freburger, J., Callahan, L., Currey, S., \& Anderson, L. (2003). Use of the Trust in Physician Scale in patients with rheumatic disease: psychometric properties and correlates of trust in the rheumatologist. Arthritis and Rheumatism, 49(1), 51-58. http://doi.org/10.1002/art.10925

Glaeser, E., Laibson, D., Scheinkman, J., \& Soutter, C. (2000). Measuring Trust. Quarterly Journal of Economics, 115, 811-846.

Grossman, S., \& Hart, O. (1983). An analysis of the principal-agent problem. Econometrica, 51, $7-46$.

Hall, M. A., Dugan, E., Zheng, B., \& Mishra, A. K. (2001). Trust in physicians and medical institutions: what is it, can it be measured, and does it matter? The Milbank Quarterly, 79(4), 613-39-v. http://doi.org/10.1111/1468-0009.00223

Herbert, H. K., Lee, A. C., Chandran, A., Rudan, I., \& Baqui, A. H. (2012). Care Seeking for Neonatal Illness in Low- and Middle-Income Countries: A Systematic Review. PLoS Medicine, 9(3), e1001183. http://doi.org/10.1371/journal.pmed.1001183

Hillen, M. A., de Haes, H. C. J. M., \& Smets, E. M. A. (2011). Cancer patients' trust in their physician-a review. Psycho-Oncology, 20(3), 227-241. http://doi.org/10.1002/pon.1745

Holm, H., \& Nystedt, P. (2008). Trust in surveys and games - A methodological contribution on the influence of money and location. Journal of Economic Psychology, 29(4), 522-542. http://doi.org/10.1016/j.joep.2007.07.010

Holmstrom, B. (1979). Moral hazard and observability. Bell Journal of Economics, 10, 74-91.

Holmstrom, B., \& Milgrom, P. (1991). Multitask principal-agent analyses: incentives contracts, asset ownership and job design. Journal of Law, Economics and Organization, 7, 24-52. http://doi.org/10.2307/764957

James, H. S. (2002). The trust paradox: A survey of economic inquiries into the nature of trust and trustworthiness. Journal of Economic Behavior and Organization, 47(3), 291-307. http://doi.org/10.1016/S0167-2681(01)00214-1

Johansson-Stenman, O., Mahmud, M., \& Martinsson, P. (2013). Trust, trust games and stated trust: Evidence from rural Bangladesh. Journal of Economic Behavior and Organization, 
95, 286-298. http://doi.org/10.1016/j.jebo.2011.06.022

Johnson, N. D., \& Mislin, A. A. (2011). Trust games: A meta-analysis. Journal of Economic Psychology, 32(5), 865-889. http://doi.org/10.1016/j.joep.2011.05.007

Johnston, A. M., Mills, C. M., \& Landrum, A. R. (2015). How do children weigh competence and benevolence when deciding whom to trust? Cognition, 144, 76-90. http://doi.org/10.1016/j.cognition.2015.07.015

Kankeu, H. T., \& Ventelou, B. (2016). Socioeconomic inequalities in informal payments for health care: An assessment of the 'Robin Hood' hypothesis in 33 African countries. Social Science \& Medicine, 151, 173-186. http://doi.org/10.1016/J.SOCSCIMED.2016.01.015

Karlan, D. S. (2005). Using Experimental Economics to Measure Social Capital and Predict Financial Decisions. American Economic Review, 95(5), 1688-1699. http://doi.org/10.1257/000282805775014407

Knack, S., \& Keefer, P. (1997). Does Social Capital Have an Economic Payoff? A CrossCountry Investigation. The Quarterly Journal of Economics, 112(4), 1251-1288. http://doi.org/10.1162/003355300555475

Krumpal, I. (2013). Determinants of social desirability bias in sensitive surveys: a literature review. Quality \& Quantity, 47(4), 2025-2047. http://doi.org/10.1007/s11135-011-9640-9

Larzelere, R. E., \& Huston, T. L. (1980). The Dyadic Trust Scale: Toward Understanding Interpersonal Trust in Close Relationships. Journal of Marriage and the Family, 42(3), 595. http://doi.org/10.2307/351903

LaVeist, T. A., Isaac, L. A., \& Williams, K. P. (2009). Mistrust of Health Care Organizations Is Associated with Underutilization of Health Services. Health Services Research, 44(6), 2093-2105. http://doi.org/10.1111/j.1475-6773.2009.01017.x

Lee, Y. Y., \& Lin, J. L. (2011). How much does trust really matter? A study of the longitudinal effects of trust and decision-making preferences on diabetic patient outcomes. Patient Education and Counseling, 85(3), 406-412. http://doi.org/10.1016/j.pec.2010.12.005

Mechanic, D., \& Meyer, S. (2000). Concepts of trust among patients with serious illness. Social Science \& Medicine, 51(5), 657-68.

Mohanan, M., Vera-Hernández, M., Das, V., Giardili, S., Goldhaber-Fiebert, J. D., Rabin, T. L., ... Seth, A. (2015). The know-do gap in quality of health care for childhood diarrhea and pneumonia in rural India. JAMA Pediatrics, 169(4), 349-57. http://doi.org/10.1001/jamapediatrics.2014.3445

Mooney, G. G., \& Ryan, M. (1993). Agency in Health Care : Getting beyond first principles. Journal of Health Economics, 2(2), 125-135. http://doi.org/10.1016/0167-6296(93)900238

Murray, B., \& McCrone, S. (2015). An integrative review of promoting trust in the patientprimary care provider relationship. Journal of Advanced Nursing, 71(1), 3-23. http://doi.org/10.1111/jan.12502

Ozawa, S., \& Walker, D. G. (2011). Comparison of trust in public vs private health care providers in rural Cambodia. Health Policy and Planning, 26(Suppl. 1), i20-i29. http://doi.org/10.1093/heapol/czr045 
Paulhus, D. L. (1991). Measurement and control of response bias. In Measures of personality and social psychological attitudes (pp. 17-59). Elsevier. http://doi.org/10.1016/B978-0-12590241-0.50006-X

Putnam, R. (1993). The Prosperous Community: Social Capital and Public Life. The American Prospect, (13).

Saha, S., Jacobs, E. A., Moore, R. D., \& Beach, M. C. (2010). Trust in Physicians and Racial Disparities in HIV Care. AIDS Patient Care and STDs, 24(7), 415-420. http://doi.org/10.1089/apc.2009.0288

Sapienza, P., Toldra-Simats, A., \& Zingales, L. (2013). Understanding Trust. The Economic Journal, 123(573), 1313-1332. http://doi.org/10.1111/ecoj.12036

Schechter, L. (2007). Traditional Trust Measurement and the Risk Confound: An Experiment in Rural Paraguay. Journal of Economic Behavior and Organization, 62(2), 272-292. http://doi.org/10.1016/j.jebo.2005.03.006

Thom, D. H., Ribisl, K. M., Stewart, A. L., \& Luke, D. A. (1999). Further validation and reliability testing of the Trust in Physician Scale. The Stanford Trust Study Physicians. Medical Care, 37(5), 510-7.

WB. (2016). Data | The World Bank. Retrieved November 8, 2016, from http://data.worldbank.org/

Zaheer, A., McEvily, B., \& Perrone, V. (1998). Does Trust Matter? Exploring the Effects of Interorganizational and Interpersonal Trust on Performance. Organization Science, 9(2), 141-159. http://doi.org/10.2307/2640350

Zhao, D. H., Rao, K. Q., \& Zhang, Z. R. (2016). Patient trust in physicians: Empirical evidence from Shanghai, China. Chinese Medical Journal, 129(7), 814-818. http://doi.org/10.4103/0366-6999.178971 